\title{
BMJ Open Understanding care when cure is not likely for young adults who face cancer: a realist analysis of data from patients, families and healthcare professionals
}

\author{
Charlotte Kenten, ${ }^{1}$ Nothando Ngwenya, ${ }^{1}$ Faith Gibson, ${ }^{2,3}$ Mary Flatley, ${ }^{4}$ \\ Louise Jones, ${ }^{5}$ Susie Pearce, ${ }^{6}$ Geoff Wong, ${ }^{7}$ Kath M Black, ${ }^{8}$ Sue Haig, ${ }^{9}$ \\ Rachael Hough, ${ }^{10}$ Adam Hurlow, ${ }^{11}$ L Caroline Stirling, ${ }^{12}$ Rachel M Taylor, ${ }^{1}$ \\ Adrian Tookman, ${ }^{13}$ Jeremy Whelan ${ }^{14}$
}

To cite: Kenten C, Ngwenya N, Gibson F, et al. Understanding care when cure is not likely for young adults who face cancer: a realist analysis of data from patients, families and healthcare professionals. BMJ Open 2019;9:e024397. doi:10.1136/ bmjopen-2018-024397

- Prepublication history and additional material for this paper are available online. To view these files, please visit the journal online (http://dx.doi. org/10.1136/bmjopen-2018024397).

CK and NN contributed equally.

Received 24 May 2018

Revised 3 November 2018

Accepted 13 December 2018

Check for updates

(C) Author(s) (or their employer(s)) 2019. Re-use permitted under CC BY-NC. No commercial re-use. See rights and permissions. Published by BMJ.

For numbered affiliations see end of article.

Correspondence to Professor Jeremy Whelan; jeremy.whelan@nhs.net

\section{ABSTRACT}

Objectives To understand the experiences of young adults with cancer for whom cure is not likely, in particular what may be specific for people aged 16-40 years and how this might affect care.

Design We used data from multiple sources (semi-structured interviews with people with cancer, nominated family members and healthcare professionals, and workshops) informed by a preliminary programme theory: realist analysis of data within these themes enabled revision of our theory. A realist logic of analysis explored contexts and mechanisms affecting outcomes of care.

Setting Three cancer centres and associated palliative care services across England.

Participants We aimed for a purposive sample of 45 people with cancer from two groups: those aged 16-24 years for whom there may be specialist cancer centres and those 16-40 years cared for through general adult services; each could nominate for interview one family member and one healthcare professional. We interviewed three people aged 16-24 years and 30 people 25-40 years diagnosed with cancer (carcinomas; blood cancers; sarcoma; central nervous system tumours) with a clinician-estimated prognosis of $<12$ months along with nominated family carers and healthcare professionals. 19 bereaved family members and 47 healthcare professionals participated in workshops.

Results Data were available from 69 interviews (33 people with cancer, 14 family carers, 22 healthcare professionals) and six workshops. Qualitative analysis revealed seven key themes: loss of control; maintenance of normal life; continuity of care; support for professionals; support for families; importance of language chosen by professionals; and financial concerns.

Conclusions Current care towards end of life for young adults with cancer and their families does not meet needs and expectations. We identified challenges specific to those aged 16-40 years. The burden that care delivery imposes on healthcare professionals must be recognised. These findings can inform recommendations for measures to be incorporated into services.

\section{Strengths and limitations of this study}

- In response to the lack of empirical research, policy and expert practice to inform delivery of optimal care for young adults when cure of their cancer is not likely, we collected data directly from patients with incurable cancer, and their nominated family carers and healthcare professionals.

- We used realist evaluation to seek the underlying mechanisms in our data and how these influenced outcomes.

- People with blood cancers and those aged between 16 and 24 years were difficult to recruit and may have unrecognised specific needs.

- Although analysis of this unique data set has highlighted specific challenges for young adults, their families and healthcare professionals in the delivery of end-of-life care, additional work is needed to make changes to practice that will improve experience and outcomes.

\section{BACKGROUND}

Cancer in young adults under 40 years is notable because it comprises a wide range of malignancies, has specific challenges to improving both length and quality of life, but is relatively uncommon. ${ }^{1}$ One quarter of all deaths in the UK in people aged 16-40 years are from cancer. ${ }^{2}$ In Europe, there are $>27000$ deaths per year in this age group. ${ }^{3}$ Despite increasing empirical evidence of the specific needs of young adults in specialist cancer care, there is little evidence about their experiences towards the end of life. ${ }^{4-6}$

Studies of adults with cancer usually cover a wide age range with most participants aged $>40$ years. The existing literature tends to summarise good practice and, where studies have been undertaken, little evidence comes directly from people with cancer. ${ }^{7-10}$ Given 
the identified gap in current literature, this research aims to contribute to Ngwenya et al.'s conclusion that 'future research should focus on age-specific evidence about the end-of-life experiences and preferences for young adults with cancer and their informal carers'. ${ }^{5}$

Concerns about improving end-of-life care are not confined to young adults. A recent interdisciplinary report published by the Royal College of Physicians in the UK summarises the concerns expressed by professionals, patients, families and other stakeholders such as charities. This report suggests that much more can be done to overcome barriers and myths that have been long identified. The value of the perspective brought by patients and families is highlighted as a means to bring timeliness and honesty to discussions about dying while at the same time accounting for and respecting specific circumstances set by factors such as underlying disease, faith and as addressed here, age. ${ }^{11}$

Boundaries between curative and palliative cancer treatments are often blurred as decisions may be influenced by cancer type, age and family circumstances as well as the experience and skills of healthcare professionals (HCPs). Avoidance and delaying of discussions about planning for care as heath deteriorates and end-oflife decisions are common, often affecting the quality of care. ${ }^{12}$ Professionals consistently acknowledge the challenges of managing end-of-life care for younger people, which may have commonalities with and, importantly, differences from those people with cancer at older ages as death approaches. ${ }^{9} 1013$

This work considers both the problem of limited data available in the literature and the desirability of understanding the experience of facing a poor prognosis at a young age from multiple perspectives. We wished to understand what were the core components in the pathways of care in the last year of life for people with cancer aged 16-40 years; whether there were any differences between the experiences of people with cancer from the age ranges 16-24 and 25-40 years; how young adults and their families can be supported in the last year of life to achieve their preferences for care; and what challenges exist for health and social care professionals providing care.

To develop our knowledge of end-of-life care in adolescents and young adults aged 16-40 years (referred to in this paper as 'young adults') with cancer, we sought to collect data directly from young adults who were facing a poor prognosis, their families and HCPs involved in their care. To gain a deep understanding of the contexts that may be specific to this age group, we chose to explore our data using a realist evaluation approach. ${ }^{14} \mathrm{~A}$ realist evaluation approach focuses on explanations, taking account of contexts and mechanisms that may affect outcomes. It addresses questions about what works for whom, in what circumstances and in what respects, and how?

Consistent with the realist evaluation approach, we began our research with a preliminary programme theory. A programme theory is a description, in words or diagrams, of what is supposed to be done in a policy or programme (theory of action) and how and why that is expected to work (theory of change) ${ }^{15}$ Details about how to develop programme theories are beyond the scope of this paper but methodological guidance is available. ${ }^{16}$ Our preliminary programme theory was informed by expert opinion within our research team which was led by clinical academic specialists in the care of young adults with cancer. Our thinking was also informed by a narrative review of the existing literature, phase I of our study, previously reported. ${ }^{5}$ A preliminary programme theory provides an initial framework of understanding for the area of research being considered. Being preliminary it is, by definition, subject to iterative change and refinement based on the data we collected and analysed. We anticipated that some elements of our preliminary programme theory may be strengthened and others refuted; indeed, new elements may emerge that require significant additions to what is thought to be our best understanding at the outset. At the end of the project, our expectation was that we would be able to develop and confirm, refute or refine aspects of preliminary programme theory and ensure that it is more realist in nature. That is, we wanted to ensure that at the close of the project we had a programme theory that contained as many realist causal explanations (ie, consisting of embedded Context-Mechanism-Outcome (CMO) configurations) within it as was possible.

Our preliminary programme theory was

that there are specific differences in experiences of and preferences for care towards the end-of-life for those with cancer aged 16-24 and 25-40 years compared to those who are older. Life-threatening illness in the young is untimely, it disrupts expected biographies, and maintaining a sense of control and normality in everyday life may be important. The role of close family members is complex and integral to the experiences of the person with cancer.

We used this theory to develop topics for use in semi-structured interviews with young adults with cancer, family members and HCPs, and to underpin scenarios used in workshop discussions with HCPs and bereaved family members. That is, our preliminary programme theory sets out our initial hypotheses of the differences we thought were likely to set apart the end-of-life care experiences and preferences for younger people. Our interviews were thus developed by the project team in such a way as to be able to gather data that would enable us to confirm, refute or refine aspects of our programme theory. For example, because we hypothesised that a sense of control might influence end-of-life care experiences, we deliberately developed interview questions that asked about this issue. An important point about our initial programme theory is that it was refined as the evaluation progressed based on data gathered. As such, our expectation was that our preliminary programme theory would need to be refined to have adequate explanatory value. 


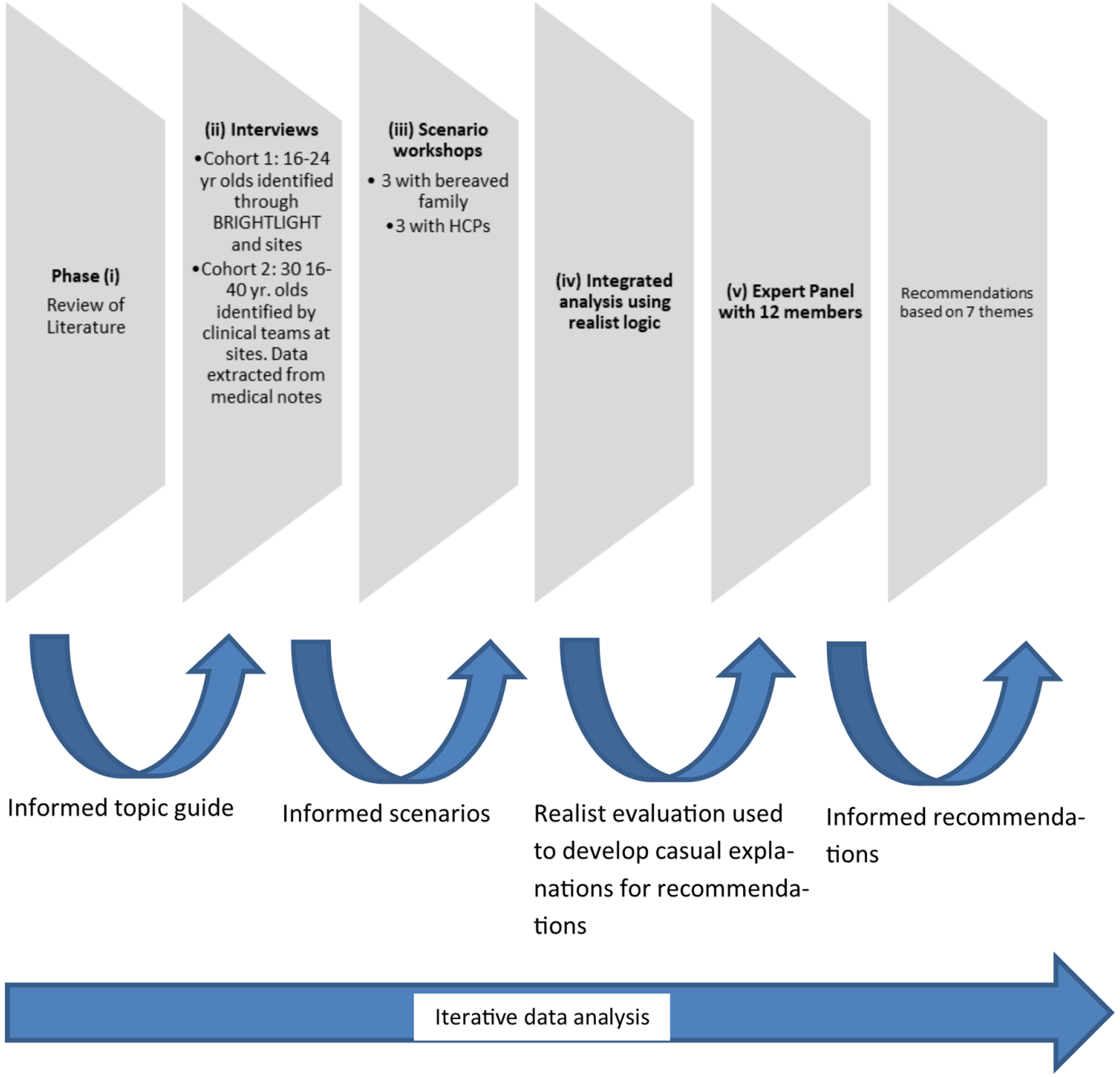

Figure 1 Phases of research process. Phases II-IV are reported here.

In this paper, we describe data arising from these interviews and workshops. We used our data analysis to further explore and develop realist causal explanations that may explain parts of our preliminary programme theory. As is expected in realist evaluations, as the evaluation progressed, we developed a revised programme theory that can be used to underpin recommendations for policy and practice and inform future research.

\section{METHODS}

A multi-method realist study was undertaken (figure 1). A realist evaluation approach was used as we wanted to explain and understand contextual influences on the experiences of and preferences for care towards the end of life for those with cancer aged 16-24 and 25-40. Here we report on phases II-IV, using RAMESES standards for reporting realist evaluations. ${ }^{17}$ Phase $\mathrm{V}$ will be reported separately.

\section{Recruitment and participants}

We aimed to recruit a purposive sample of young people aged 16-40 with cancer, in two cohorts with an expected prognosis of $<1$ year, across four cancer groups: carcinomas; leukaemia and lymphoma; bone and soft tissue sarcoma; and central nervous system (CNS) tumours, which account for more than three-quarters of cancers occurring in this age group. Estimation of prognosis was made at each site by clinicians involved in screening and identifying people with cancer for the study. They used clinical records, their own clinical knowledge of disease progression and liaised with other members of the clinical team to confirm, at the time of approach, that the prognosis for each individual was likely to be $<1$ year. In cohort 1, we planned to recruit a maximum of 15 participants aged 16-24 years, including a minimum of three participants from each of the cancer groups, to be interviewed at two time points; recruitment began via a national cohort study investigating whether specialist cancer services add value (http://www.brightlightstudy. com) and was later extended, due to poor recruitment, to include five principal treatment centres and a hospice for young adults. Cohort 2 was recruited from three specialist cancer services and three hospices in England and consisted of a maximum sample of 30 participants between the ages of 16-40. All cohort 2 participants were invited to nominate a family member and HCP involved 
in their care for interview. The first-hand clinical experience of many in the project team aided the development of the study. Knowing that this is an under-researched population within the context of the study and drawing on professional experience to guide data collection, analysis and interpretation was essential. Further details are available in the protocols (online supplementary files 1 and 2).

\section{Data collection}

\section{Semi-structured interviews}

All participants took part in a semi-structured interview at a single time point using a topic guide. Cohort 1 participants were invited to take part in a later second interview. ${ }^{14}$ The topic guide was developed from a review of the limited existing literature for the 16-40 age range ${ }^{5}$ and the clinical and academic expertise within the project team who work directly with this population. We sought patient and public involvement input to refine the topic guide coverage and phrasing of the questions, which explored medical, social, communication and decision-making experiences for people with cancer and their families. We asked HCPs to reflect on the care of the person with cancer and their practice with those approaching the end of life.

\section{Workshops}

We held workshops in London, Southampton and Leeds. The workshops involved the participants sitting as one group. One clinical member of the team acted as the facilitator for the HCP workshops and two clinical members of the team were co-facilitators for the bereaved relative workshops. The co-facilitation meant that if someone from the group needed to leave or have a break from the discussion they could be supported by one of the co-facilitators while the workshop was able to continue. At the start of the workshop the facilitator introduced the study, outlined the workshop and informed consent obtained. The HCP workshops focused around the scenarios and the perspectives of different professional roles. The bereaved relative groups were guided by one of the facilitators with the participants sharing narratives around their experiences with other participants either supporting the narrative or outlining how their experience differed.

\section{Healthcare professionals}

Three workshops involved HCPs working in both hospital and community settings who were recruited by the participating sites. Two scenarios were developed from initial interview analysis and reported experiences (table 1). We sought to present contrasting fictional patients differing by age, gender and social situations which had raised a number of common issues arising from the interview data that the workshop participants were asked to discuss.

\section{Bereaved relatives}

We held three workshops with bereaved relatives who were invited to take part by bereavement services in participating hospices. The use of scenarios for this group were felt to be too abstract; and so these workshops focused on the relatives' individual experiences. The workshops involved open discussions and sought to collect information that had not emerged previously in the interviews, particularly concerning the last days of life.

All patient, family and HCP participants were provided with a Participant Information Sheet which outlined the study, their expected involvement and the right to withdraw at any point. Written informed consent was obtained from all those who participated in the study. Interviews and workshops were audio-recorded, transcribed verbatim and anonymised before analysis. Field notes were recorded during the workshops.

\section{Data analysis}

Data were entered into a qualitative analysis software programme, NVivo V.10 to facilitate analysis. ${ }^{18}$ A realist evaluation approach enabled us to identify and understand (a) the outcomes for young people receiving care, (b) when these outcomes were likely to occur (the contexts) and (c) why (the mechanism).${ }^{14}$ Our analysis was multistaged (figure 2):

- Stage 1 -identification of emergent themes. Charmaz's grounded theory approach was used. ${ }^{19}$ Initial codes (summary of what participants were describing) were open and inductive from the data using verbatim quotes or researcher-generated codes to inform a conceptual framework. We then developed categories by grouping similar codes. The categories were identified by two researchers working independently. Emergent findings were discussed within the wider research team and further refined into themes.

- Stage 2-realist logic of analysis. This stage was undertaken as we wanted to develop findings that had a clear warrant for transferability. In other words, by reanalysing our themes, using a realist logic of analysis, we would be able to identify the commonly occurring mechanisms within this population group that caused the outcome patterns we had found. The way we operationalised a realist logic to develop CMO configurations may be found in online supplementary file 3 .

Reanalysis and reinterpretation of the themes to develop CMO configurations was undertaken by $\mathrm{CK}$ and NN aided by data analysis meetings with LJ, SP, FG and GW. To assist the reanalysis and reinterpretation process, we attempted to develop CMO configurations that explained the outcomes in as many parts as possible of our preliminary programme theory; of the care pathways and experiences of people with cancer, family members and HCPs. For each of these mini programme theories, we reanalysed the data that we drew on to develop each theme to build CMO configurations; that is, develop realist causal explanations of outcomes that occurred within different contexts (eg, social rules and cultural systems). Workshop data were analysed in the same two-step manner and used to confirm, refute or refine the CMO configurations within the 'mini' programme theories. 


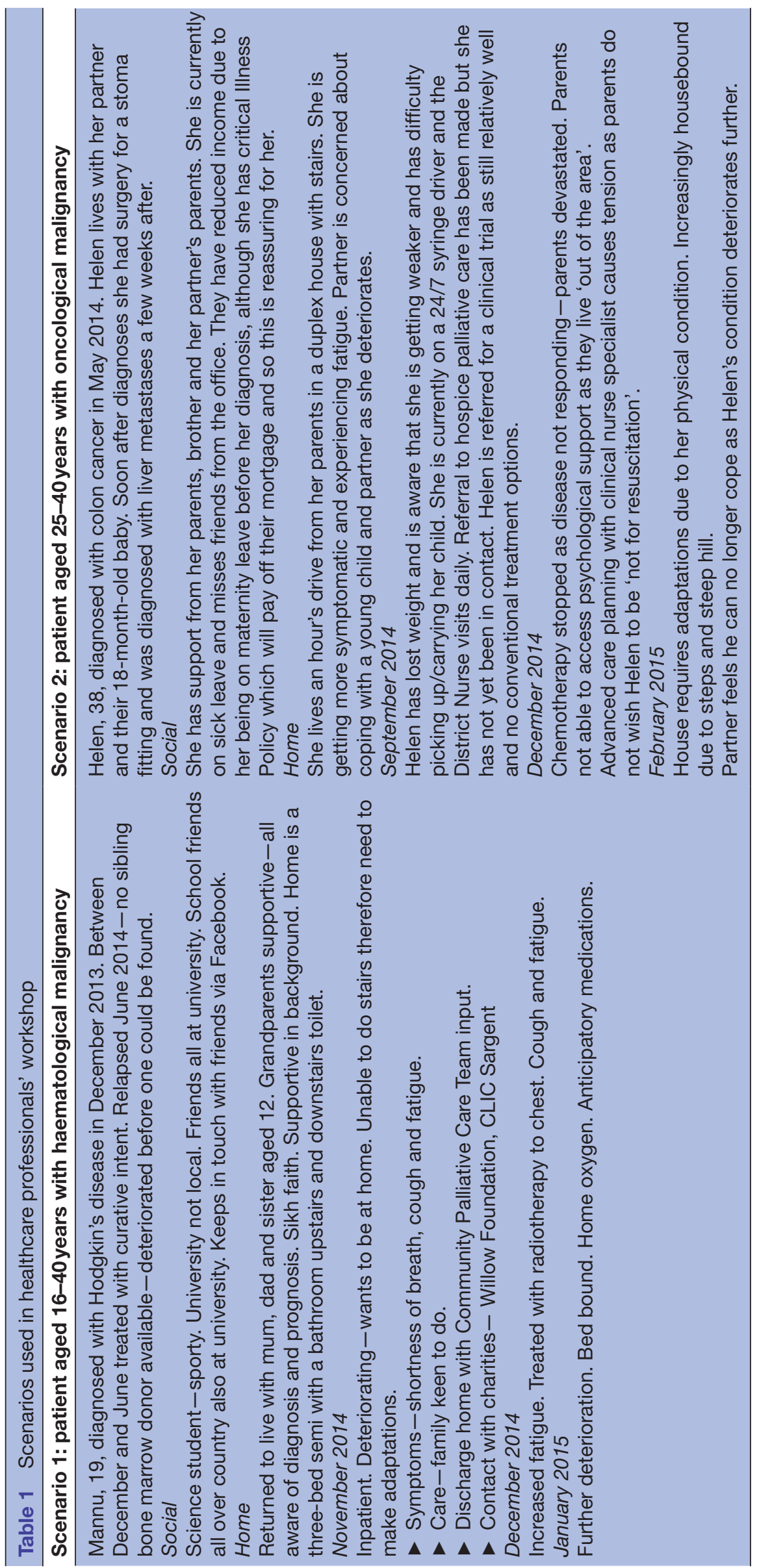




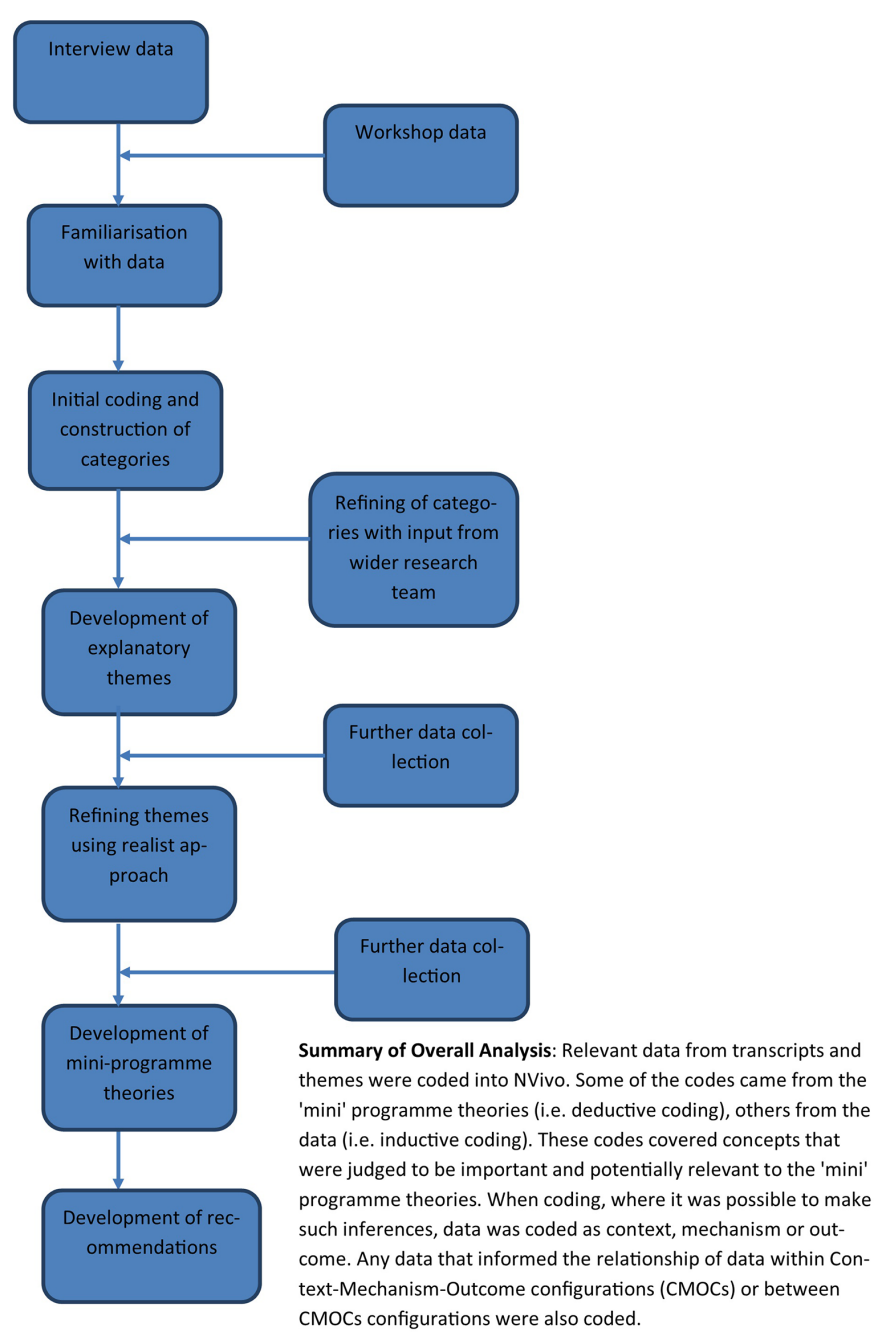

Figure 2 Analysis process.

\section{Patient and public involvement}

We responded to a funding call from Marie Curie, a UK charitable organisation which provides care and support to people with terminal illnesses and their families, specifically seeking research proposals focused on the needs of young adults. We sought the views of people with cancer on study design and written information including patient information sheets through the Cancer Partnership Research Group of the Surrey, West Sussex and Hampshire Cancer Network and the National Cancer Research Network Consumer Group. An independent steering committee, which included a bereaved parent of a young adult, provided advice and oversight on study conduct. We plan to work with Marie Curie on patient-focused dissemination of our findings.

\section{RESULTS}

Table 2 summarises the participants by cohort. A total of 69 interviews were conducted (33 people with cancer, 14 family members, 22 HCPs); 19 bereaved family members and 47 HCPs took part across six workshops.

The results are presented in three sections:

1. Our thematic analysis of qualitative participant data.
2. Realistic logic of analysis reporting CMO configurations developed from reanalyses of the themes.

3 . The connections and links between contexts, mechanisms and outcomes as leading to the revision of our programme theory.

\section{Section 1: thematic analysis}

Seven key themes emerged each of which is accompanied by one or more illustrative verbatim section of texts from our data.

\section{Loss of control}

As illness progressed and young adults with cancer became more debilitated, they often felt a loss of control over how they lived their lives. This was a shift from independence to a growing dependence on others for physical, emotional, practical or financial support provided by family, friends, HCPs or the wider state. The future became unpredictable and planning was difficult. Maintaining a sense of control and continuing to take part in activities, although compromised, was important:

My independence. For me, being able to do things on my own is definitely something that I miss, without being carefree, I can't be carefree, I can't just go out and have, get drunk with friends any more. I can't go out for a long night and dress up in heels and get bashed about, because I have a port in, I've got cancer, you know, I have to go and sit down at a bar, have a non-alcoholic cocktail. It doesn't mean I can't socialise and have a good time with them, I still do. But I'm uncomfortable when I dress up now, whereas before I had the figure and went to the gym and felt more comfortable in myself. (Cohort 2-patient 20)

\section{Maintenance of normal life}

Participants all desired to continue, as far as possible, living a 'normal life', for example, working, taking part in activities, looking after their children. Normality provided reassurance and a sense of control but it could also be a defensive response and a shield of denial about the realities of dying from cancer. As the disease progressed, the sense of 'what was normal' needed to be reframed and adjusted:

I'm at probably the worst stage I've ever been with this illness, obviously because it's more advanced. Yet people are just saying, 'You're looking great.' And when I look in the mirror, I don't feel like I've got cancer. I don't feel like-obviously I do because I know that I do, but I don't feel any different to how I used to feel. Obviously yes you've got a few aches and pains and stuff, but you think like, when you hear someone's dying of cancer, you think that person will feel like they are. But like I know that I am, but I don't feel like I am, because it's quite a disconnect of like howyou know, like when you're feeling alright and you're going round doing stuff, and you're just doing stuff like everyone else, you just kind of forget. You go to 


\begin{tabular}{|c|c|c|}
\hline $\begin{array}{l}\text { Cohort } 1 \\
\mathrm{n}=30\end{array}$ & $\begin{array}{l}\text { Cohort } 1 \\
\mathrm{n}=30\end{array}$ & $\begin{array}{l}\text { Cohort } 2 \\
\mathrm{n}=3\end{array}$ \\
\hline \multicolumn{3}{|l|}{ Gender } \\
\hline Male & 11 & 3 \\
\hline Female & 19 & 0 \\
\hline \multicolumn{3}{|l|}{ Age } \\
\hline Median (range) years & $32(16-39)$ & \\
\hline \multicolumn{3}{|l|}{ Ethnicity } \\
\hline White British & 19 & 3 \\
\hline Any other white background & 4 & \\
\hline $\begin{array}{l}\text { Asian/Asian British/black/African/ } \\
\text { Caribbean/black British }\end{array}$ & 7 & \\
\hline \multicolumn{3}{|l|}{ Cancer type } \\
\hline Carcinoma & 18 & 1 \\
\hline Sarcoma & 6 & 2 \\
\hline Blood cancer & 2 & \\
\hline $\begin{array}{l}\text { Other (including melanoma/ } \\
\text { central nervous system) }\end{array}$ & 4 & \\
\hline \multicolumn{3}{|l|}{ Education/working } \\
\hline Working part time & 2 & \\
\hline Working full time & 2 & \\
\hline Sick leave & 9 & 2 \\
\hline Sick leave from education & 2 & 1 \\
\hline Not working/early retirement & 14 & \\
\hline \multicolumn{3}{|l|}{$\begin{array}{l}\text { Nominated, interviewed family or } \\
\text { other }\end{array}$} \\
\hline Husband/wife/partner & 5 & \\
\hline Parent/sibling & 8 & \\
\hline
\end{tabular}

Nominated, interviewed healthcare professionals

\begin{tabular}{ll} 
Clinical nurse specialist & 13 \\
General practitioner & 2 \\
Hospital doctor & 4 \\
Allied health professional & 3 \\
$\begin{array}{l}\text { Patient did not nominate } \\
\text { Healthcare professional declined }\end{array}$ & 5 \\
participation & 3 \\
\hline
\end{tabular}

work and you just have the same sort of, do the same things you were doing before you had cancer. You just forget, I forget sometimes. (Cohort 2-patient 19)

\section{Continuity of care}

Young adults valued being known by the HCPs involved in their care and preferred a joined-up care pathway between them, the HCPs and other health services. This relied on maintaining continuity of communication and information between HCPs, services and themselves with a shared knowledge of the care plan. They generally preferred to be seen by the same HCPs as they felt they could build rapport and feel known as a person. When they moved between services, for example, from oncology to palliative care or from hospital to hospice, they wanted this to be a joined-up seamless shift:

So we went into this initial meeting and [1st tumour CNS], who is the CNS, was there. And Dr [Consultant] was the one that kept us waiting. And it was said at that point, "[1st tumour CNS] will be your CNS, presumably key worker, throughout this process, she will be at every one of your appointments when you come to clinic.' And I was like, great, and he gave me her number and a pack and, you know, I felt quite supported by that. ... I understand not being able to the same nurse every time, that's not possible, but like if you had a team that were allocated a certain number of patients-because they just, they don't know you. And I've noticed that across the course of having another lot, you know, and I've really-I've kind of got to know a lot of them because I've been there, you know, over the course of a year. But, you know, it is at the beginning, it's someone different every week. And they don't know anything about you. And I went in expecting them to have read my notes, know what kind of cancer it was, know, you know, some of my background, and totally naively - they-and I think it's unfair to them, they are there just to administer medication. (Cohort 2-patient 29)

\section{PROFESSIONALS NEED SUPPORT}

Professionals in either cancer or palliative care settings tended to have greater experience of caring for older adults. They had less experience providing end-of-life care to those aged 16-40 and fewer 'tools' or strategies to offer this younger population. Professionals found caring for young adults as they deteriorated both professionally and emotionally challenging and burdensome, as witness to young people prematurely reaching the end of their lives coupled with a weight of expectation to do more. The availability, accessibility and use of support for HCPs was variable and ranged from peer to professional support with a perception that experienced senior doctors were less likely to be in need. In contrast, nurses were perceived to be more likely to require and/or seek out support:

But there's always been this sort of demarcation that when they come to the-come to, 'They're now incurable,' they go somewhere else. And that 'somewhere else' is always nebulous. 'Someone else' looks after them 'somewhere else.' Do you know what I mean? ... 'Oh they go over there now.' As I said earlier, the palliative team will look after them. And I don't think any of us [Oncology CNS] have ever really gone to see what the palliative team do or see how much input they have. And is that a, is that a lack of professionalism or is that a survival mechanism for 
ourselves? And I have a feeling it's the latter. I have a feeling that it's very much a survival mechanism for ourselves because then we can just close that bit off and we can get on over here. And we'd like to know how they are, but we don't have to be the one that tells them. (Cohort 2-HCP 16)

\section{FAMILIES NEED SUPPORT}

Families provided multiple types of support (practical, physical, emotional, financial) to the person with cancer to complement or supplement professional care:

Well I do as much for her as I can and I go out and do all her shopping. And if her husband is not around to pick the kids up from school, myself and my other daughter, we sort of take care of the kids. And also we've been taking them out as well because-and that upsets [name] more especially during the school holidays last week that they couldn't go anywhere. And she started saying, 'I'm not a good mum.' (Cohort 2-family 22)

The impending decline and death of a young family member was usually unanticipated and a situation that families have rarely experienced before. Family members generally had fewer appropriate skills to care for the person as their cancer progressed. Families expressed a wish for some form of access to information or training to care for their loved one appropriately. Looking back, bereaved families commented that their skills to deliver care at the end of life were limited and they would have liked access to some basic training and emotional support.

\section{LANGUAGE}

The use of language by HCPs to describe an approach to care may not convey the same meaning to young adults with cancer and their families. For example, words such as hospice conjured up particular scenarios and carried ambiguity about the imminence of the end of life; such terms were often left unexplained, causing distress:

I do remember him [Consultant] saying, I can't really remember the conversation massively, but I do remember him keep saying, 'Tumour, there's a tumour.' And then I literally did have to say, 'Hang on a minute, do you mean cancer?' and he said, 'Yes, we've got to run more tests and this, that and the other, but yes.' But that's the only thing I remember really about it, if you know what I mean. (Cohort 2-patient 14)

\section{FINANCIAL CONCERNS}

There were few participants for whom finance was not a concern. For those who were younger and still in education or training, the burden tended to fall on their families. For those who were working, with loans, mortgages or dependents, the impact of cancer compromised their ability to support themselves and their families. Concerns were expressed about changes in lifestyle whereby the basics were prioritised. There was some confusion around entitlement to benefits or equivalent sources of financial support and limited access to tailored financial advice or guidance:

But you could do with somebody saying to you, in the first place, 'You need somebody to help you to do this,' you know what I mean, you need somebody who can guide you through the system. And I think the same applied with [name]. He'd think, 'Oh well I've just got to fill this form in and I've got ...' but actually filling those forms in is a damned hard job. (Cohort 2-family 23)

You haven't asked to be in that position [dying from cancer]. So I shouldn't have to go to work and think, 'Well I'll do a monotonous job just to pay the bills to only live another few months.' If I've only got a few more months to live, I'd rather spend it with my family, you know, having the time with them. (Cohort 2-patient 6)

\section{SECTION 2: REALIST EXPLANATIONS OF OUR THEMES PRESENTED IN THE FORM OF CMO CONFIGURATIONS}

We reanalysed and reinterpreted our emergent themes using a realist logic of analysis. We attempted to identify mechanisms (generative causal processes) that are activated in the contexts we had found within the themes we uncovered. Our interview data were purely qualitative and so likely to be limited in the range of relevant data needed to build CMO configurations. To supplement these data, we deliberately drew on the extensive content expertise of the project team, workshops and where relevant, existing theories on needs of people living with cancer.

Details summarising the CMO configurations are presented in table 3 .

\section{Section 3: revision of preliminary programme theory}

Our reanalyses of the data enabled us to confirm, further develop and refine aspects of our preliminary programme theory-namely control, normality and family support. We were also able to add to our preliminary programme theory the concepts of continuity, professional support, language and financial support. In what follows, we summarise important aspects of our refined programme theory.

\section{Age-specific issues}

We now understand that for those aged 16-40 there are specific differences between the end-of-life care experience and preferences. However, rather than being wholly defined by age, the stages in a young person's life course may be a better way to approach, understand and support these differences.

\section{Maintenance of control and sense of normality}

Our data underpin these concepts within our preliminary programme theory. We have learnt that young adults with 


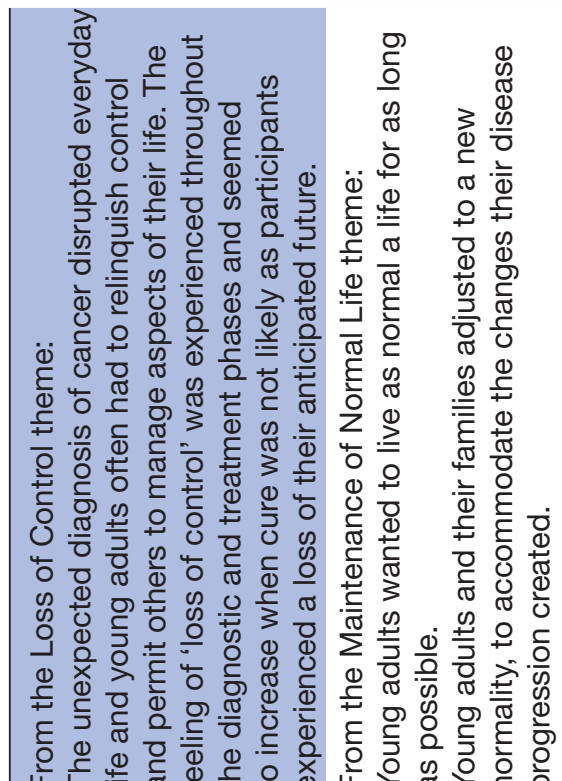

음

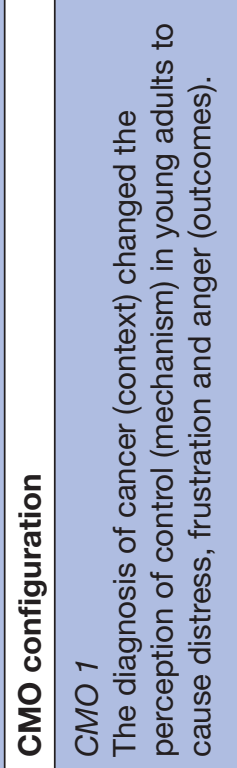

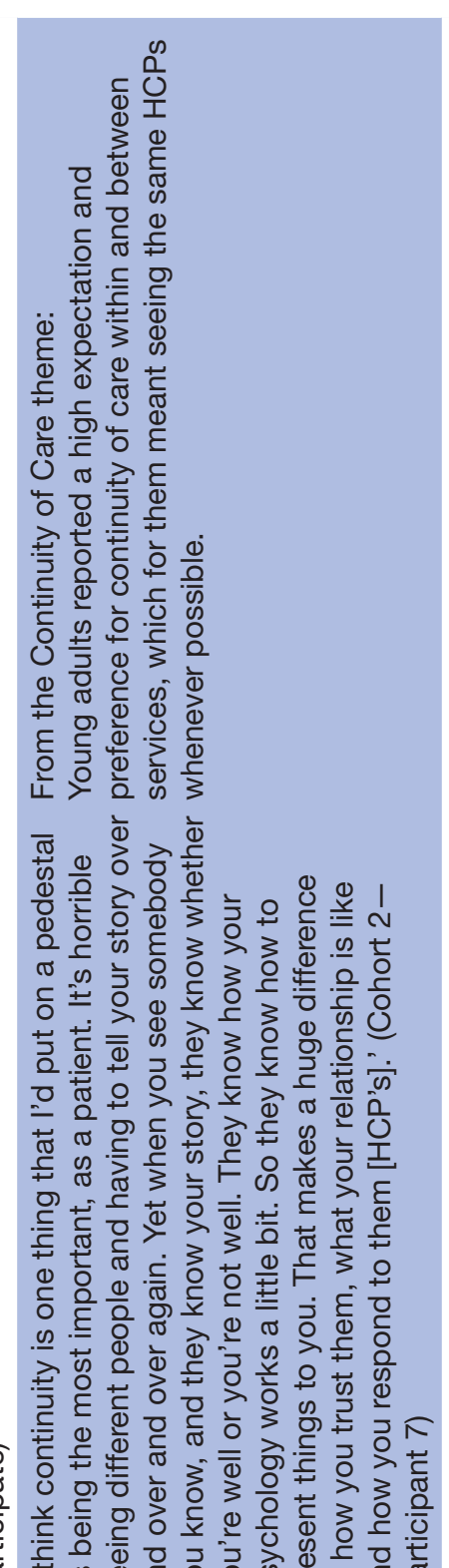

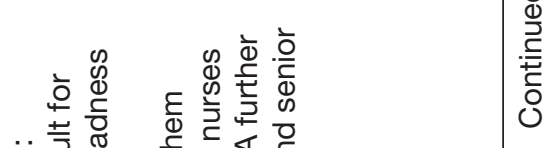

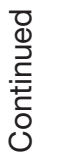

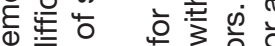

和 $ᄃ$ के

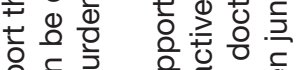

으ㅇㅝㅛ

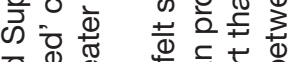

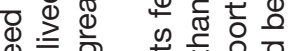

$\sum \geqq \pi \quad \overline{0}$

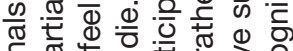

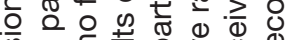

क

ㅎำ

पे

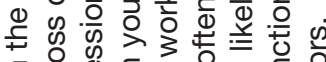

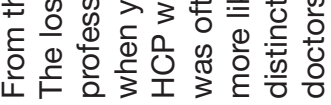

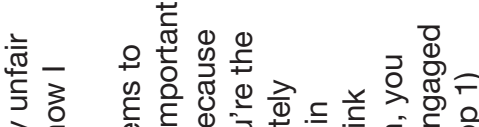

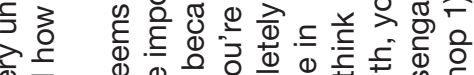

过

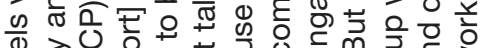

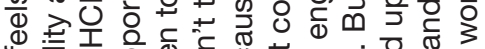

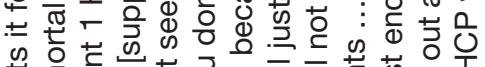

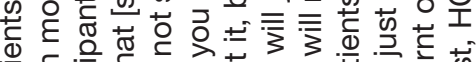

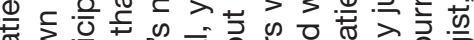

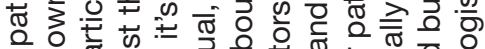

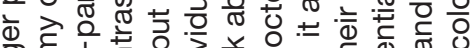
बही 亏

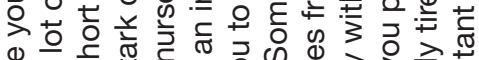

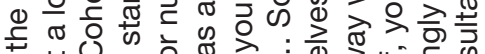
पँ

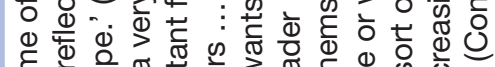

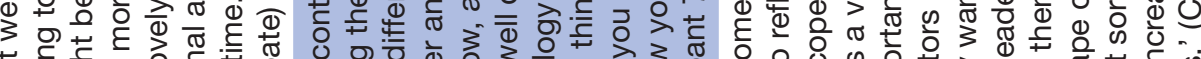

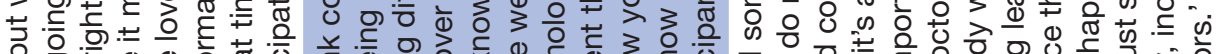

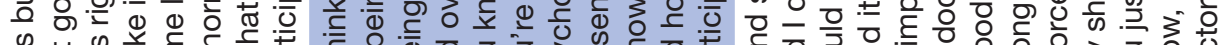

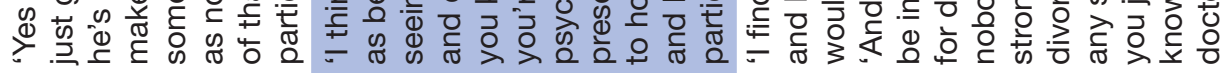

ำ

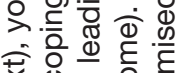

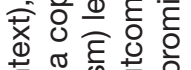

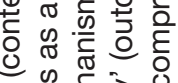

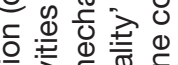

을 弄要

늉 흥ㅎㅇ.

ठ ত

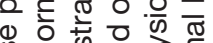

की

舟

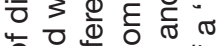

O

×

는

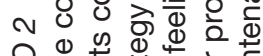

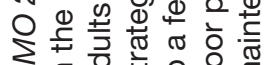

흠

강

ᄃิ ฮ ह

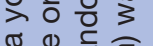

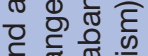

ฮิ ส

i 0 ○

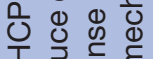

I 귱 है

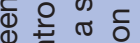

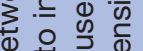

ه

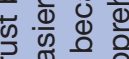

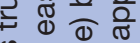

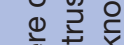

3 范

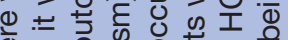

के

๓

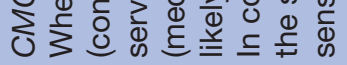

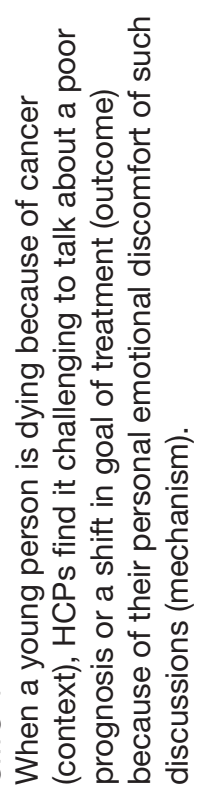




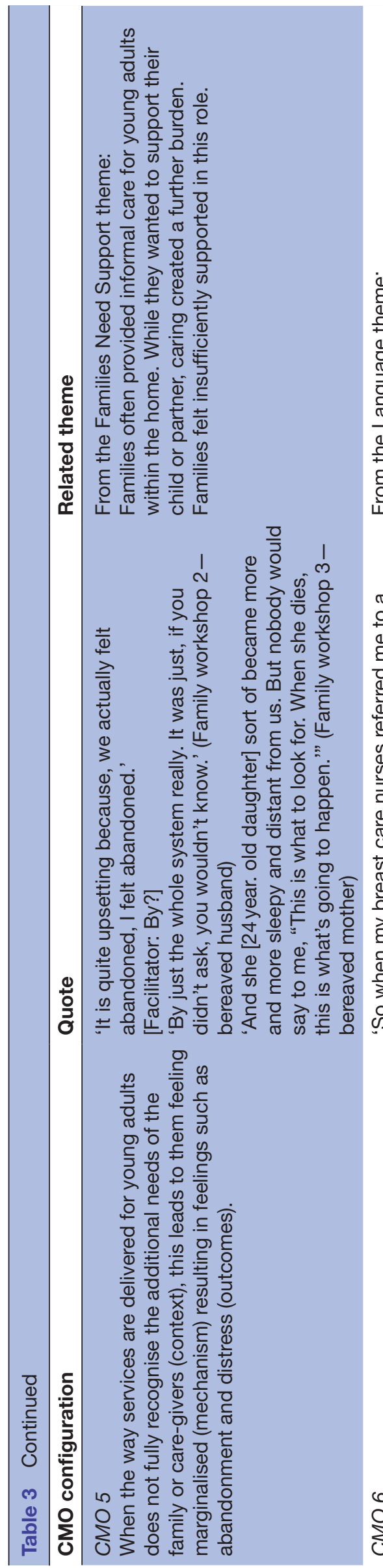

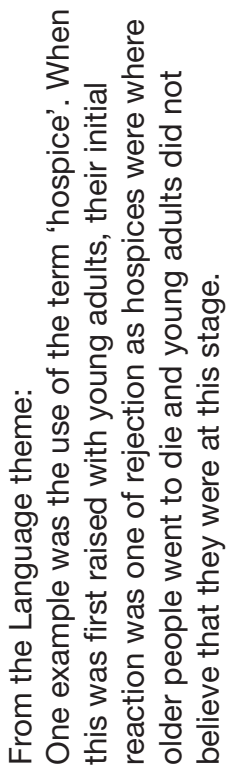

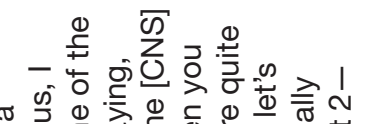
๙

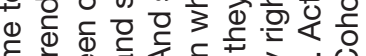

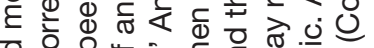

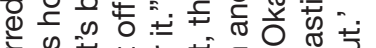

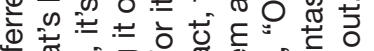

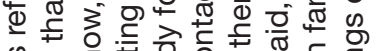
\&

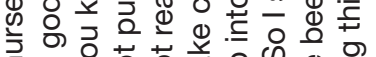

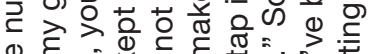

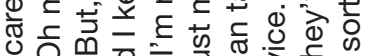

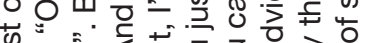

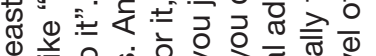

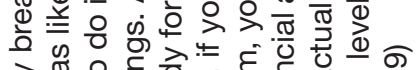

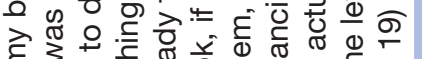

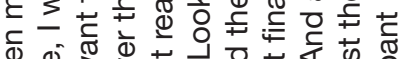

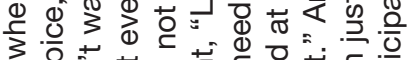

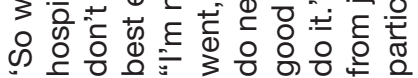

$4 \frac{1}{\pi}$

要 舟

을 엉

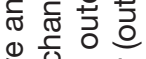

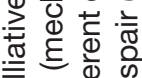

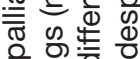

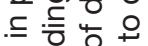

ชำ 뜽

क क क

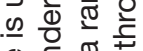

ब.

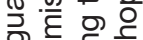

宁 安 ?

(1)

芒苍芌

है

워

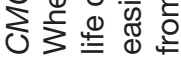

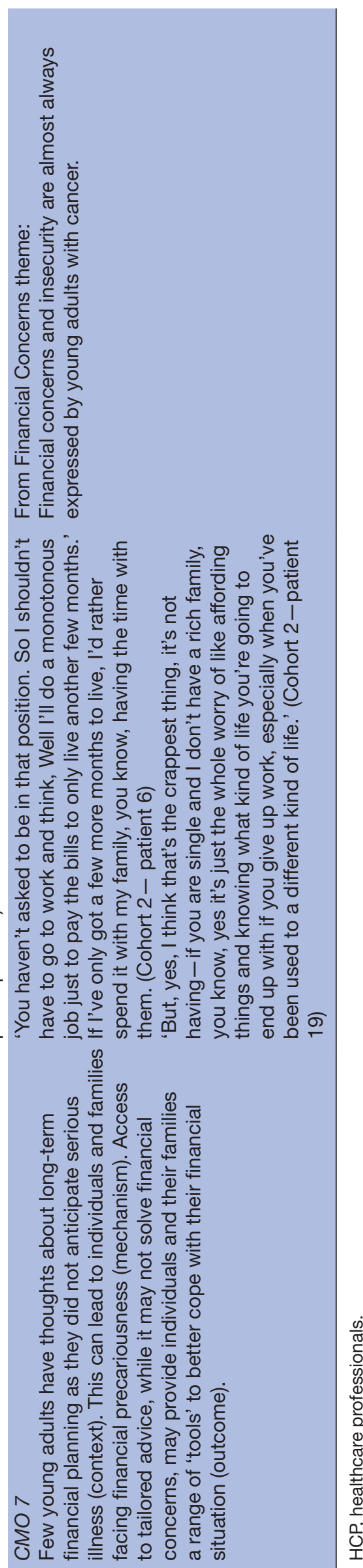


cancer need support to put strategies in place to retain control and live as normally as possible while providing a space to discuss and plan for their shortened future.

\section{Families of younger people with cancer}

We found that the family often are not appropriately equipped to provide the level of care and support that they want to provide during the last year of life of the young adult with cancer and lack the means to be 'skilled-up' for this role.

\section{HEALTHCARE PROFESSIONALS}

We found that HCPs lack age (16-40years) life course-specific knowledge to develop strategies to support patients in their last year of life and their families.

\section{DISCUSSION}

In this study, we used a realist evaluation approach to gain a deeper understanding of the particular contexts that may be specific to the experiences of young adults aged 16-40 years with cancer as they approached their end of life. We reanalysed our initial seven themes into seven $\mathrm{CMO}$ configurations that explained the specific needs of the end-of-life experiences of young adults with cancer. The implications of these specific needs are set out below and compared and contrasted with the existing literature.

\section{Life course and not age matters}

We found that within this group end-of-life experiences and preferences cannot be neatly isolated into the two age ranges we studied (16-24 years and 25-40 years). A better way of approaching, understanding and supporting young adults may be to consider where they are in their life course, as there may be more in common, than different, between those with similar life course experiences, for example, being in education, maintaining a career, having children or caring responsibilities. The usefulness of taking such an approach is also found in the wider literature on end-of-life care for young adults and so reinforces this finding. ${ }^{20}$ Adolescence and young adulthood is a developmental stage when individuals shape their identities, gain autonomy, make career choices and develop intimate relationships. A cancer diagnosis at this stage is 'off-time' during the normative life cycle: life is interrupted, developmental tasks and identity formation are challenged and few peers will share their cancer experience. ${ }^{20}$ In common with Soanes and Gibson, we found that participants across this age range reported a desire to maintain these aspects of their life, as well as their identity, for example, as a student, a professional or parent, in part to maintain a sense of normality and control. ${ }^{21}$

\section{Giving young people the chance to have control and to feel normal}

We found, perhaps unsurprisingly, the pivotal role of HCPs in supporting young adults with cancer. However, we were able to identify that an important 'block' to the support provided comes from the emotional discomfort felt by HCPs when discussing aspects of care specifically with young adults - such as discussions about prognosis. This is important as a cancer diagnosis creates great uncertainty and the knowledge that there will not be a cure creates a dissonance between the life that was expected and the reality of a life that will be significantly shorter than expected. For emerging adults and early independent adults, as disease progresses, dissonance is also present as their independence is compromised with an increasing and unanticipated dependence on others. This can affect their ability to attend school, college or work as well as taking part in family or social activities or fulfilling caring duties for others, for example, looking after young children. Adaptation is a mechanism through which there is a recognition of what can no longer be achieved due to disease progression. ${ }^{22}$ An adapted normality can be achieved together with a sense of control, allowing for realistic goal setting. ${ }^{23}$ Advance care planning could facilitate this adaptation. However, few participants in our study reported having had conversations about their options or the care they wanted to receive. Some HCPs avoided such conversations because of the emotional burden to themselves, not wishing to challenge either hope or a young person's possible denial about their situation. This might be an example of what Bell et al refer to 'as social constraint', that is, words and actions that inhibit end-of-life discussions. ${ }^{24} \mathrm{~A}$ further notable finding from the data indicates that all parties appear to wait for another to raise the topic of end of life. The 'window of opportunity ${ }^{17}$ often fails to appear, thus in some cases the topic is avoided. This has the potential to delay adaptation and limit the time available for professional support, which could help young adults plan and make as much as possible of remaining time. ${ }^{25}$ For those with dependents, particularly young children, delaying adaptation could impact on their roles as parents, delaying the opportunity to prepare and create memories for themselves and their families. ${ }^{23}$ When end of life was addressed, this tended to be when health had deteriorated, and that window of opportunity, although late, facilitated opportunities to discuss the future, end-of-life care and to make plans.

\section{Families and carers matter even more}

Data from family members came from two perspectivesboth before and into bereavement. Many family members became informal caregivers. We found increased dependence on family members whether emotionally, physically, financially or for support with housing. The level of independence varied between the two age groups with those aged 16-24 more likely to be living in the parental home, still in education or receiving training and moving towards becoming independent from their family. Those aged 25-40 were more likely to have been independent adults for longer. In common with Knox et al, we also found that when thrust back into dependent relationships with parents, left behind by peers, whom they perceived to be moving forward with their own life goals, young adults could feel isolated. ${ }^{26}$ The financial burden of cancer is 
widespread, but for those at the younger end of the age group who were still in education or living at home, the burden fell more heavily on their family. For those with greater independence and who relied on their income from employment, a cancer diagnosis compromised their ability to work and maintain their lifestyle. It is likely that older people with cancer, particularly those who have retired with an income to cover their regular expenses, may not face such financial extremes. Mohammed et al refer to caregivers 'taking charge', thrust into a role for which they often felt ill-prepared ${ }^{27}$ In our study, lack of understanding of the clinical situation due to confidentiality, a lack of practical or technical knowledge or skills and poor information from HCPs, themselves often reluctant to undertake end-of-life discussions, were some of the contextual influences contributing to feeling ill-prepared, abandoned or distressed.

\section{The burdens for HCPs}

Professionals reported difficulty addressing the needs of both the person with cancer and their family as often they had different expectations. Professionals were aware that providing bereavement support to a family was difficult if they had not built a relationship with them in the limited time available. This is mirrored by our finding that continuity mattered much more to young adults. Managing complex family dynamics was challenging for HCPs and strategies to do this were often not addressed. Sometimes HCPs did not want to 'open a can of worms' by involving the family as they were aware that they would have to consider extra care needs, not viewed as part of their role. This was a strategy used by HCPs to manage their workload and families were not told that it was acceptable to ask for help and support. Professionals preferred to maintain and share optimism with the family, maintaining hope, all of which helped to reduce the emotional discomfort they would otherwise feel. So, talking openly about the death of the person with cancer was rarely pursued. Beerbower et al refer to 'a broken system of communication' that can lead to conflict, where there has been no disclosure of prognosis, or where disclosure has for some family members only been partial, or come much too late. ${ }^{20} 28$ Educating, enabling and supporting caregivers can thus be complex and challenging, reinforcing the need for early and developmentally appropriate communication.

Professionals often have less exposure to and experience of providing end-of-life care for young adults. They are likely to be similar in age to the person with cancer, their family or friends, enhancing the emotional difficulties of working with this population. While in palliative care end-of-life might be 'normal', caring for those aged 16-40 who are dying will not be normal nor will facing the loss of lives partially lived. The avoidance by HCPs of engaging in the challenging discussions and activities we have already listed is understandable. But Wiener et al point out that HCPs need to reflect and be aware of the emotional effect that younger patients have on them and whether the support they offer is relevant and enabling of this population to continue to live normally for as long as possible. ${ }^{29}$ Clark et al have suggested that providing a developmentally appropriate approach to care that includes advance decision making is thus essential. ${ }^{30}$ To enable HCPs to meet the needs of the end-of-life care of young adults, formal support is needed. However, the formal support for HCPs in their professional roles varied in availability, access and was used differently. There was a distinction between doctors and nurses. Participants in our study suggested that the emotional burden received greater recognition in the nursing profession whereas for senior doctors there was little or no provision of support and an expectation that they would not show the emotional effect of their work. There were also issues about having the time to access support, associated costs and the lack of visibility and advocacy from senior HCPs for accessing support. In addition, support was not integrated into training or ongoing professional practice and for some senior HCPs it may have been regarded as compromising their role or authority. ${ }^{31}$ Self-care in the palliative care workforce is known to be essential, yet rarely is education or training available. ${ }^{32}$ We would agree with Knox et al that palliative care services should consider prioritising resources to support self-care practice, to promote the health and well-being of HCPs. ${ }^{18}$

\section{Strengths, limitations and future research directions}

Although our study is unusual for the extensive data collected from young adults facing end of life and their triangulation with family and HCPs, recruitment of two groups of patients was unsatisfactory. Young adults with haematological malignancies were rarely invited to participate despite these being a commoner diagnosis in this population. This may be because those with haematological diagnoses continue to be offered and agree to receive 'curative' treatments. ${ }^{34}$ When such curative options had been exhausted, our participants were often 'actively dying' and too ill to participate in this study. Another under-represented group were those aged 16-24. Professionals suggested that while clinical teams identified young adults meeting the study eligibility criteria, the challenges of communicating that 'cure was not likely' may have impacted on their reluctance to introduce the study. Our original plan to undertake two interviews with participants failed: often patients were just too unwell for a second interview. We cannot be certain that the data presented in this paper wholly reflects the experiences of these two populations, neither can we be certain of 'completeness' or 'informational redundancy', in these accounts; we are however more certain that 'conceptual depth' was reached. ${ }^{35}$ Further research is needed to explore the needs of those often described as 'hard to reach', and those with haematological cancers and those aged 16-24 years. A further limitation arises from the recognised difficulties in estimating life expectancy so that study participants could not be accurately assessed as being within the last year of life and so some caution about their representativeness is necessary. 


\section{CONCLUSION}

We identified challenges with the way current end-of-life care is delivered to young adults with cancer. Using this evidence, recommendations to improve care can now be developed.

\section{Author affiliations}

${ }^{1}$ Cancer Clinical Trials, University College Hospitals NHS Foundation Trust, London, UK

${ }^{2}$ ORCHID, Great Ormond Street Hospital For Children NHS Trust, London, UK

${ }^{3}$ School of Health Sciences, University of Surrey, Guildford, UK

${ }^{4}$ St Joseph's Hospice, London, UK

${ }^{5}$ Division of Psychiatry, Marie Curie Palliative Care Research Department, University

College London, London, UK

${ }^{6}$ School of Nursing and Midwifery, University of Plymouth Faculty of Health and Human Sciences, Plymouth, UK

${ }^{7}$ Nuffield Department of Primary Care Health Sciences, University of Oxford, Oxford, UK

${ }^{8}$ Academic Unit of Palliative Care, St Gemma's Hospice, Leeds, UK

${ }^{9}$ Southampton General Hospital, Southampton, UK

${ }^{10}$ Children and Young Peoples Cancer Service, University College London Hospitals

NHS Foundation Trust, London, UK

${ }^{11}$ Palliative Care, Leeds Teaching Hospitals NHS Trust, Leeds, UK

${ }^{12}$ Palliative Medicine, Camden, Islington ELiPSe and UCLH \& HCA Palliative Care

Service, London, UK

${ }^{13}$ Marie Curie Hospice Hampstead, Marie Curie Cancer Care, London, UK

${ }^{14}$ University College London Hospitals NHS Foundation Trust, London, UK

Acknowledgements The authors are grateful for the contributions of all those who participated in the study and for the assistance of healthcare professionals at each site who identified or approached young adults about the study. They are grateful to Dr Teresa Tate, Professor Paddy Stone, Dr Jo Armes and Mr John Reeve for their advice and oversight of the study as members of the External Steering Committee.

Contributors All authors were all involved in study design, review of results and review of this manuscript. Interviews and analysis were conducted by CK and NN: aided by data analysis meetings with LJ, SP, FG and GW. Workshops were attended by CK, NN, MF, LCS, RH, FG, JW. KB and ABH attended 1 workshop and led another Participant recruitment was assisted by MF, KB, SH, AH, LCS and JW.

Funding This study was supported by Marie Curie grant reference MCCC-RP13-A15722. This paper presents a companion study to BRIGHTLIGHT, which is independent research funded by the National Institute for Health Research (NIHR) under its Programme Grants for Applied Research Programme (grant reference number RP-PG-1209-10013). GW's salary is partly supported by the Evidence Synthesis Working Group of the National Institute for Health Research School for Primary Care Research (NIHR SPCR) (Project Number 390).

Disclaimer The views expressed are those of the author(s) and not necessarily those of the NHS, the NIHR or the Department of Health.

Competing interests None declared.

Patient consent for publication Not required.

Ethics approval The study was approved by Central London research ethics committee (REC reference: 13/L0/1098).

Provenance and peer review Not commissioned; externally peer reviewed.

Data sharing statement No data from interviews with patients, families and healthcare professionals are available in the public domain given the potential for identification of sensitive information.

Open access This is an open access article distributed in accordance with the Creative Commons Attribution Non Commercial (CC BY-NC 4.0) license, which permits others to distribute, remix, adapt, build upon this work non-commercially, and license their derivative works on different terms, provided the original work is properly cited, appropriate credit is given, any changes made indicated, and the use is non-commercial. See: http://creativecommons.org/licenses/by-nc/4.0/.

\section{REFERENCES}

1. Bleyer A, Ferrari A, Whelan J, et al. Global assessment of cancer incidence and survival in adolescents and young adults. Pediatr Blood Cancer 2017;64:e26497.
2. What are the top causes of death by age and gender? $2012 \mathrm{http}: / /$ webarchive.nationalarchives.gov.uk/20160105221750/http://www. ons.gov.uk/ons/rel/vsob1/mortality-statistics-deaths-registered-inengland-and-wales-series-dr-/2012/sty-causes-of-death.html (Cited 02 Aug 2016).

3. Globocan. Estimated Cancer Incidence, Mortality and Prevalence Worldwide in 2012. $2012 \mathrm{http}: / /$ globocan.iarc.fr/Pages/fact sheets population.aspx (Cited 02 Aug 2017).

4. Rosenberg AR, Wolfe J. Palliative care for adolescents and young adults with cancer. Clin Oncol Adolesc Young Adults 2013;2013:41-8.

5. Ngwenya N, Kenten C, Jones L, et al. Experiences and preferences for end-of-life care for young adults with cancer and their informal carers: a narrative synthesis. J Adolesc Young Adult Oncol 2017:6:200-12.

6. Bleyer A, Barr R, Ries L, Whelan J, Ferrari A, et al. eds. Cancer in adolescents and young adults. 2nd edn. Switzerland: Springer, 2017.

7. Grinyer A. Palliative and end of life care for children and young people: home, hospice, hospital. Wiley: Oxford, 2012.

8. Grinyer A, Thomas C. The importance of place of death in young adults with terminal cancer. Mortality 2004;9:114-31.

9. Kars MC, Grypdonck MH, de Bock LC, et al. The parents' ability to attend to the "voice of their child" with incurable cancer during the palliative phase. Health Psychol 2015;34:446-52.

10. Kars MC, Grypdonck MH, de Korte-Verhoef MC, et al. Parental experience at the end-of-life in children with cancer: 'preservation' and 'letting go' in relation to loss. Support Care Cancer 2011;19:27-35

11. Royal College of Physicians Our Future health. Talking about dying: How to begin honest conversations about what lies ahead. London: Royal College of Physicians, 2018.

12. Baker JN, Hinds PS, Spunt SL, et al. Integration of palliative care practices into the ongoing care of children with cancer: individualized care planning and coordination. Pediatr Clin North Am 2008;55:223-50.

13. Grinyer A, Barbarachild Z. Teenage and young adult palliative and end of life care service evaluation. London, 2011.

14. Pawson R, Tilley N. Realistic evaluation. London: Sage Publications Ltd, 1997:235;23.

15. The Rameses II Project. "Theory" in realist evaluation. $2017 \mathrm{http}: / /$ ramesesproject.org/pgm-download_media.php?name=RAMESES_II Theory_in_realist_evaluation.pdf.

16. The Rameses II Project. Developing Realist Programme Theories. $2017 \mathrm{http}: / / \mathrm{ramesesproject.org/pgm}$-download_media.php?name= RAMESES_II_Developing_realist_programme_theories.pdf.

17. Wong G, Westhorp G, Manzano A, et al. RAMESES II reporting standards for realist evaluations. BMC Med 2016;14:96.

18. Richards L. Qualitative S, Research. Using NVivo in qualitative research. London: Sage, 1999:218.

19. Charmaz K. Grounded Theory: objectivist and constructivist methods. In: Denzin NK, Lincoln YS, eds. Handbook of qualitative research. California: Sage Publications Ltd, 2000:1065.

20. Beerbower E, Winters D, Kondrat D. Bio-psycho-social-spiritual needs of adolescents and young adults with life-threatening illnesses: Implications for social work practice. Soc Work Health Care 2018:57:250-66.

21. Soanes L, Gibson F. Protecting an adult identity: a grounded theory of supportive care for young adults recently diagnosed with cancer. Int J Nurs Stud 2018;81:40-8.

22. Livneh H. Psychosocial adaptation to cancer: the role of coping strategies. Journal of Rehabilitation 2000;66:40-50.

23. Nissim R, Rennie D, Fleming S, et al. Goals set in the land of the living/dying: a longitudinal study of patients living with advanced cancer. Death Stud 2012;36:360-90.

24. Bell CJ, Zimet GD, Hinds PS, et al. Refinement of a conceptual model for adolescent readiness to engage in end-of-life discussions. Cancer Nurs 2018:41:E21-E39.

25. Llewellyn H, Neerkin J, Thorne L, et al. Social and structural conditions for the avoidance of advance care planning in neurooncology: a qualitative study. BMJ Open 2018;8:e019057.

26. Knox MK, Hales S, Nissim R, et al. Lost and stranded: the experience of younger adults with advanced cancer. Support Care Cancer 2017;25:399-407.

27. Mohammed S, Swami N, Pope A, et al. "I didn't want to be in charge and yet I was": bereaved caregivers' accounts of providing home care for family members with advanced cancer. Psychooncology 2018;27:1229-36.

28. Bell CJ, Skiles J, Pradhan K, et al. End-of-life experiences in adolescents dying with cancer. Support Care Cancer 2010;18:827-35. 
29. Wiener L, Weaver MS, Bell CJ, et al. Threading the cloak: palliative care education for care providers of adolescents and young adults with cancer. Clin Oncol Adolesc Young Adults 2015;5:1-18.

30. Clark JK, Fasciano K. Young adult palliative care: challenges and opportunities. Am J Hosp Palliat Care 2015;32:101-11.

31. Bradford NK, Greenslade R, Edwards RM, et al. Educational needs of health professionals caring for adolescents and young adults with cancer. J Adolesc Young Adult Oncol 2018;7:298-305.

32. Mills J, Wand T, Fraser JA. Self-care in palliative care nursing and medical professionals: a cross-sectional survey. J Palliat Med 2017;20:625-30.
33. Mills J, Wand T, Fraser JA. Examining self-care, selfcompassion and compassion for others: a cross-sectional survey of palliative care nurses and doctors. Int J Palliat Nurs 2018:24:4-11.

34. Odejide OO, Cronin AM, Earle CC, et al. Why are patients with blood cancers more likely to die without hospice? Cancer 2017;123:3377-84

35. Saunders B, Sim J, Kingstone T, et al. Saturation in qualitative research: exploring its conceptualization and operationalization. Qual Quant 2018;52:1893-907. 